\title{
Structure-selective accumulation of polychlorinated biphenyls in Cucurbita pepo
}

\author{
Shinryo Matsuo ${ }^{\dagger}$, Kiyoshi YAMAZAKI ${ }^{\dagger}$, Keiko GION ${ }^{\dagger \dagger}$, Heesoo EuN ${ }^{\dagger \dagger \dagger}$ and Hideyuki InUI ${ }^{\dagger}, \dagger^{\dagger}, *$ \\ ${ }^{\dagger}$ Graduate School of Agricultural Science \\ ${ }^{\dagger}$ Research Center for Environmental Genomics Kobe University, 1-1 Rokkodaicho, Nada-ku, Kobe, Hyogo 657-8501, Japan \\ ${ }^{\dagger \dagger}$ Chemical Analysis Research Center, National Institute for Agro-Environmental Sciences, \\ 3-1-3 Kannondai, Tsukuba, Ibaraki 305-8604, Japan
}

(Received January 17, 2011; Accepted March 23, 2011)

\begin{abstract}
Nine zucchini cultivars (Cucurbita pepo subspecies ovifera and pepo) were grown in soil containing a mixture of dioxins and dioxin-like compounds. Plants of subspecies pepo accumulated polychlorinated dibenzo-p-dioxins (PCDDs), polychlorinated dibenzofurans (PCDFs), and polychlorinated biphenyls (PCBs) in their aerial parts at higher concentrations than did plants of subspecies ovifera. In all cultivars, the accumulation of PCDDs and PCDFs in the aerial parts decreased with increasing hydrophobicity, whereas for PCBs, a negative correlation was observed in only two cultivars. The other seven cultivars selectively accumulated ortho-chlorinated biphenyls. Our results contribute to the understanding of the mechanisms underlying these phenomena, which should help in the development of efficient methods for phytoremediation of hydrophobic contaminants. (C) Pesticide Science Society of Japan
\end{abstract}

Keywords: bioconcentration factors, Cucurbita pepo, persistent organic pollutants, polychlorinated biphenyls.

\section{Introduction}

Persistent organic pollutants (POPs) remain in the environment for a long time owing to their hydrophobicity and chemical stability, and they spread widely under the influences of natural phenomena such as prevailing winds. Although POPs are present at low concentrations in the environment, they accumulate in organisms through the food chain, eventually reaching concentrations that are toxic to mammals, including humans. ${ }^{1)}$ Many kinds of chemical substances are classified as POPs, including dichlorodiphenyltrichloroethane, dioxins, and dioxin-like compounds. ${ }^{2}$

Dioxins and dioxin-like compounds are classified as PCDDs, PCDFs, or coplanar PCBs on the basis of their structural features. There are many congeners with different numbers and binding positions of chlorine atoms, and the various congeners exhibit different toxicities. Accumulation of these compounds in mammals is thought to result in carcinogenicity, teratogenicity, immunotoxicity, and reproductive toxicity. ${ }^{3)}$ Therefore, efficient new technologies for remediation of diox-

\footnotetext{
* To whom correspondence should be addressed.

E-mail: hinui@kobe-u.ac.jp

Published online June 4, 2011

(C) Pesticide Science Society of Japan
}

ins and dioxin-like compounds are needed because the currently used physical and chemical remediation methods are costly. Recently, phytoremediation has become popular because plants can absorb and accumulate chemical substances at low concentrations from wide areas via the root system; ${ }^{4)}$ however, most plants cannot accumulate POPs owing the high hydrophobicity of these compounds. ${ }^{5)}$

Zucchini (Cucurbita pepo) plants reportedly extract hydrophobic chemicals, including POPs, from soil more efficiently than other plant species. ${ }^{5,6)}$ For example, some zucchini plants accumulate chlordane, ${ }^{7)}$ drins, ${ }^{5}{ }^{5}$ 1,1-dichloro-2,2bis ( $p$-chlorophenyl) ethylene (DDE) ${ }^{8}$ ) and heavy metals ${ }^{9)}$ in their aerial parts at higher concentrations than other plant species. Moreover, subspecies-level variation in phytoextraction of DDE by C. pepo has been reported. ${ }^{10)}$ Structure-selective accumulation has also been observed for chlordane ${ }^{11)}$ and dioxins and dioxin-like compounds. ${ }^{12)}$ The compositional profiles of chiral (trans-chlordane and cis-chlordane) and achiral (trans-nonachlor) chlordane differ among the root, xylem, and aerial parts of zucchini plants, suggesting that the transport mechanisms are enantioselective. ${ }^{11)}$ In zucchini cultivars that are high accumulators of dioxins and dioxin-like compounds, bioconcentration factors (BCFs) for mono-ortho-chlorinated biphenyls are several times as high as those for PCBs without chlorine at the ortho position, whereas no such structural de- 
pendence has been observed in tobacco or in the low-accumulating zucchini cultivar, ${ }^{12)}$ however, the mechanisms underlying the high and selective accumulation of POPs in zucchini plants are not fully understood. Clarification of these mechanisms will aid in the development of novel methods for efficient phytoremediation of hydrophobic contaminants.

In this study, we investigated the mechanisms of structure selectivity by evaluating the accumulation of PCDDs, PCDFs, and PCBs by nine zucchini cultivars grown in soil contaminated with dioxins and dioxin-like compounds.

\section{Materials and Methods}

\section{Plant materials}

Seeds of $C$. pepo subspecies ovifera and pepo were purchased from Johnny's Selected Seeds (Albion, ME, USA). Seeds of C. pepo L. subspecies pepo 'Black Beauty' (BB) were purchased from Tanenomori (Saitama, Japan). Table 1 lists the nine cultivars and their subspecies, abbreviations, numbers of plants, and \% DDE phytoextracted. ${ }^{10)}$

\section{Soil}

Concentrations of PCDDs, PCDFs, and PCBs in weathered soil contaminated with dioxins and dioxin-like compounds at 7600 ng-toxic equivalent (TEQ) $\mathrm{kg}^{-1}$ and collected from the periphery of an incinerator were quantified by the method described after Soxhlet extraction (Supplemental Table S1), ${ }^{12)}$ and the soil was then used for cultivation of plants.

\section{Cultivation of plants in contaminated soil}

The soil was air dried in a draft at room temperature for a week and homogenized with a soil-mixing machine (PT40SMV; Mazelar Co., Ltd., Niigata, Japan), and sieved to $<2$ $\mathrm{mm}$. The homogenous soil was used for pot experiments and analysis of dioxins and dioxin-like compounds. Seeds were soaked in tap water at $4^{\circ} \mathrm{C}$ for 8 days and then transferred to

Table 1. The nine cultivars of C. pepo used in this study

\begin{tabular}{llccc}
\hline Cultivar & Subspecies & Abbreviation & $n^{a)}$ & $\begin{array}{c}\% \text { DDE } \\
\text { phytoextracted }^{b)}\end{array}$ \\
\hline Patty Green & ovifera & PG & 4 & 0.024 \\
Starship & ovifera & ST & 3 & 0.039 \\
Sunburst & ovifera & SB & 4 & 0.027 \\
Sunray & ovifera & SR & 4 & 0.133 \\
Zephyr & ovifera & ZP & 4 & 0.076 \\
Black Beauty & pepo & BB & 4 & 0.078 \\
Gold Rush & pepo & GR & 5 & 0.780 \\
Raven & pepo & RA & 4 & 0.454 \\
Magda & pepo & MG & 3 & 0.263 \\
\hline
\end{tabular}

${ }^{a)}$ Number of plants used in this study. ${ }^{b)}$ White et al., Environ. Sci. Technol. (2003).
$200 \mathrm{~cm}^{2}$ pots each filled with $2 \mathrm{~kg}$ contaminated soil with an appropriate amount of fertilizer $(\mathrm{N}: \mathrm{P}: \mathrm{K}=6: 6: 6$; Leber Torf Co., Ltd., Osaka, Japan). The top of the soil in the pots was covered with aluminum foil to prevent vaporization of the contaminants and adhesion of soil to aerial plant parts. All plants were cultivated for 36 days from 26th May to 1st July, 2008 in a greenhouse. The greenhouse temperature was 20$40^{\circ} \mathrm{C}$ and humidity was $40-80 \%$. Aerial parts were sampled for the extraction of PCDDs, PCDFs, and PCBs.

\section{Extraction and high-resolution gas chromatography- high-resolution mass spectrometry analysis of PCDDs, PCDFs, and PCBs}

A previously reported method was used for extraction and high-resolution gas chromatography-high-resolution mass spectrometry, with a slight modification. ${ }^{12)}$ The aerial parts of the plants were each homogenized in a mixture of hexane and acetone. After separation of solution from residues, sulfuric acid was treated to remove pigment. Hexane was dried under vacuum conditions. The residual solution was applied to a hexane-equilibrated multi-layer silica gel column and active carbon silica gel column. After evaporation under a nitrogen stream, the sample was applied to a high-resolution gas chromatography-high-resolution mass spectrometry system (HP6890/ Micromass Autospec-Ultima; Micromass Ltd., Manchester, UK).

BCFs were calculated by dividing the concentration of each dioxin congener in the aerial parts of a plant by its concentration in soil. A high BCF indicates efficient accumulation in the aerial parts.

\section{Results and Discussion}

1. Accumulation of PCDDs, PCDFs, and PCBs in zucchini cultivars

There were no great differences in the fresh weights of the aerial parts among the nine zucchini cultivars grown in the contaminated soil (Fig. 1A), but there were substantial differences among the cultivars in the total concentrations of PCDDs, PCDFs, and PCBs accumulated in the aerial parts (Fig. 1B). The concentrations in the aerial parts were higher for cultivars of subspecies pepo than for cultivars of subspecies ovifera. The lowest and highest concentrations were detected in PG and MG, respectively. The results shown in Fig. 1 indicate that the concentrations of accumulated dioxins and dioxin-like compounds were not dependent on plant mass; therefore, cultivar-specific mechanisms must have been responsible for the selectivity in the uptake and accumulation of PCDDs, PCDFs, and PCBs. The concentrations of these compounds in the soil used in this study were almost the same as the soil concentrations in our previous study. ${ }^{12)}$ Therefore, the TEQ values in the aerial parts of PG, BB, and GR were on the same order of magnitude to the values in the previous study (Supplemental Table S2), indicating that there is repeatability in the accumulation of dioxins and dioxin-like 
(A)

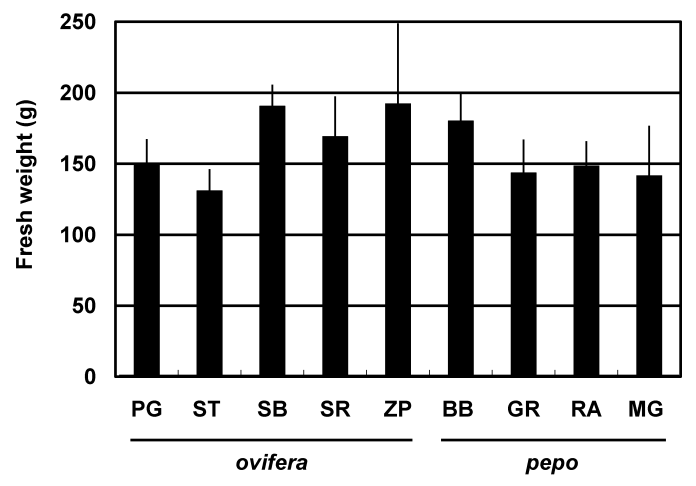

(B)

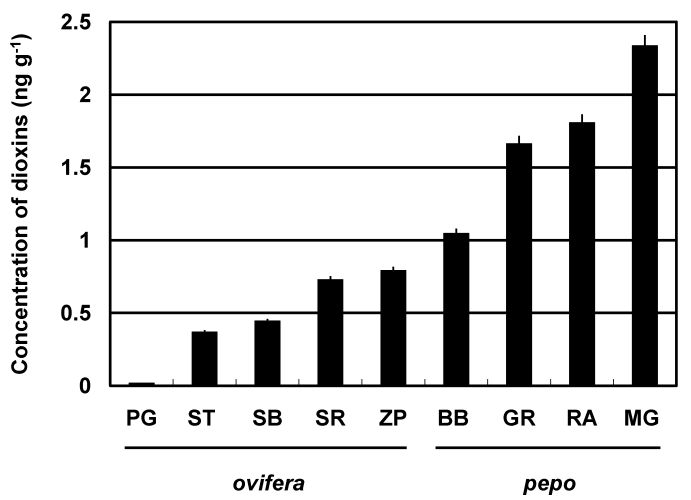

Fig. 1. Fresh weights of the aerial parts (A) and total concentrations of PCDDs, PCDFs, and PCBs accumulated in the aerial parts (B) of nine cultivars of zucchini plants grown in soil contaminated with dioxins and dioxin-like compounds. Values are the means \pm SDs.

compounds in these zucchini cultivars.

2. BCFs of PCDDs, PCDFs, and PCBs

The BCF values of the PCDDs and PCDFs in subspecies pepo were higher than the corresponding values in subspecies ovifera (Fig. 2A, B). Tetrachlorinated dibenzo-p-dioxins (TCDDs) including 2,3,7,8-TCDD, 1,3,7,9-TCDD, and 1,3,6,8-TCDD and tetrachlorinated dibenzofurans (TCDFs) including 1,2,7,8-TCDF and 2,3,7,8-TCDF were accumulated easily, whereas more highly chlorinated congeners were accumulated with difficulty. Moreover, BCFs differed even for congeners with the same number of chlorine atoms. For all nine cultivars, the correlations between the BCFs and the logarithms of the octanol-water partition coefficients $\left(K_{\mathrm{ow}}\right)$ of the PCDDs and PCDFs were negative (Table 2). These results suggest that highly hydrophobic compounds were taken up and accumulated with difficulty in the aerial parts of the plants. This decrease in the accumulation of PCDDs and PCDFs with increasing hydrophobicity was also observed in our previous study. ${ }^{12)}$ In addition, negative correlations between the hydrophobicity of various other compounds, such as $17 \beta$-estradiol ( $\left.\log K_{\text {ow }}, 4.1\right)$, methoxychlor $\left(\log K_{\text {ow }}, 4.6\right.$ ), and 4-nonylphenol $\left(\log K_{\mathrm{ow}}, 6.2\right)$, and their concentrations in the aerial parts have been reported, whereas the correlation between hydrophobicity and concentration in roots is positive. ${ }^{13,14)}$

The BCF value of each PCB in subspecies pepo was also higher than the corresponding value in subspecies ovifera (Fig. 2C). PG accumulated 3,3',4,4'-tetrachlorobiphenyl (TCB) more efficiently than the other PCB congeners, whereas the other cultivars accumulated penta- and hexachlorobiphenyls (PeCBs, HxCBs) more efficiently (Fig. 3C). Although PG and ST also showed negative correlations between BCFs and $\log K_{\text {ow }}$ values, the other seven cultivars did not (Table 2).

These results suggest that, in all cultivars, accumulation of PCDDs and PCDFs was determined by the compounds' physicochemical properties. In contrast, the finding that physicochemical property-dependent accumulation of PCBs was observed only in PG and ST suggests that accumulation of PCBs was controlled by other mechanisms in the other cultivars. Interestingly, the \% DDE phytoextracted and the $\mathrm{BCF}$ for PCDDs, PCDFs, and PCBs were correlated in the nine cultivars (Supplemental Fig. S1). This result clearly suggests that accumulation of DDE, dioxins, and dioxin-like compounds is regulated by a similar mechanism - that is, primarily by hydrophobicity, not by structure dependency.

\section{BCF patterns for congeners of PCDDs, PCDFs, and $P C B s$}

To compare accumulation in the different cultivars, we evaluated BCF patterns for the dioxins and dioxin-like compounds in each cultivar. We evaluated BCF patterns by determining the relative $\mathrm{BCF}$ for each PCDD, PCDF, and PCB congener by dividing the $\mathrm{BCF}$ of the congener by the $\mathrm{BCF}$ of $1,3,6,8$ TCDD, 2,3,7,8-TCDF, or 3,3',4,4'-TCB, respectively (that is, the corresponding congener that accumulated to the highest concentration in $\mathrm{PG}$ ).

The BCF patterns of the PCDDs and PCDFs were similar among the nine cultivars (Fig. 3A, B), although for the tetrachlorinated congeners of PCDDs and the pentachlorinated congeners of PCDFs there was little variation among the cultivars. In addition, the BCF patterns of the PCBs revealed that ortho-substituted $\mathrm{PeCBs}$ and $\mathrm{HxCBs}$ were accumulated more efficiently than were the other congeners in SB, SR, ZP, BB, GR, RA, and MG (Fig. 3C). This result suggests that the mechanisms of PCB accumulation in PG and ST differed from the accumulation mechanisms in the other cultivars. Similar findings were observed in our previous study of PG, $\mathrm{BB}$, and GR. ${ }^{12)}$

\section{Cultivar-specific mechanisms of PCDD, PCDF, and $P C B$ accumulation in $C$. pepo}

Dioxins and dioxin-like compounds bind strongly to soil organic matter because of their high hydrophobicity. Six steps are thought to be involved in the accumulation of hydrophobic contaminants into plants: (1) exudation of compounds, such as organic acids, from roots, (2) desorption and solubi- 
(A)

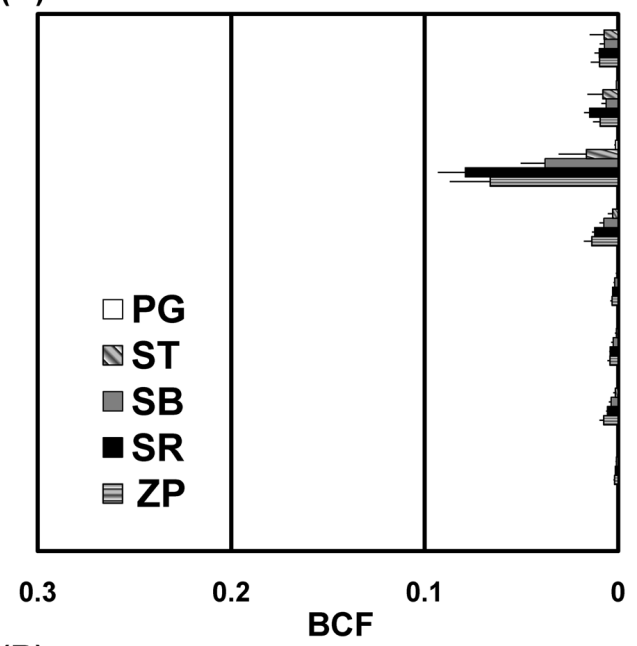

(B)

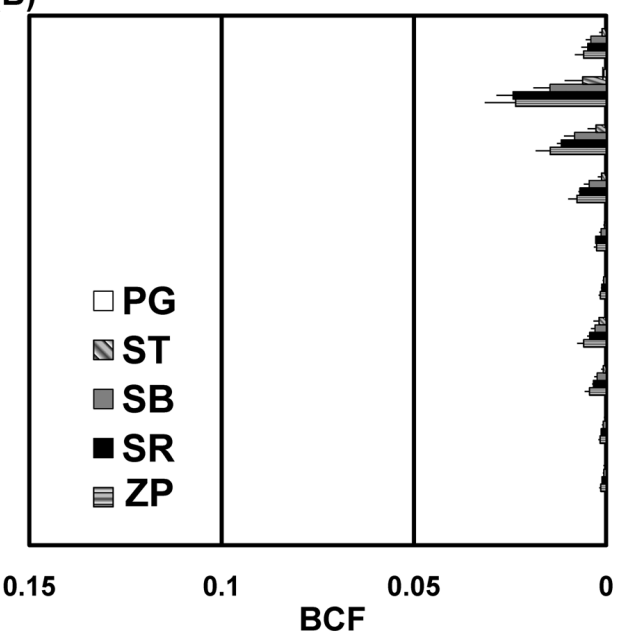

(C)

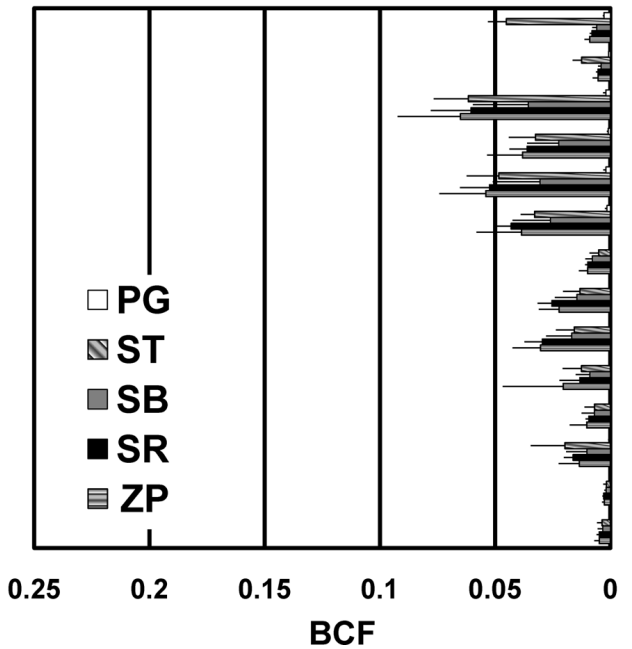

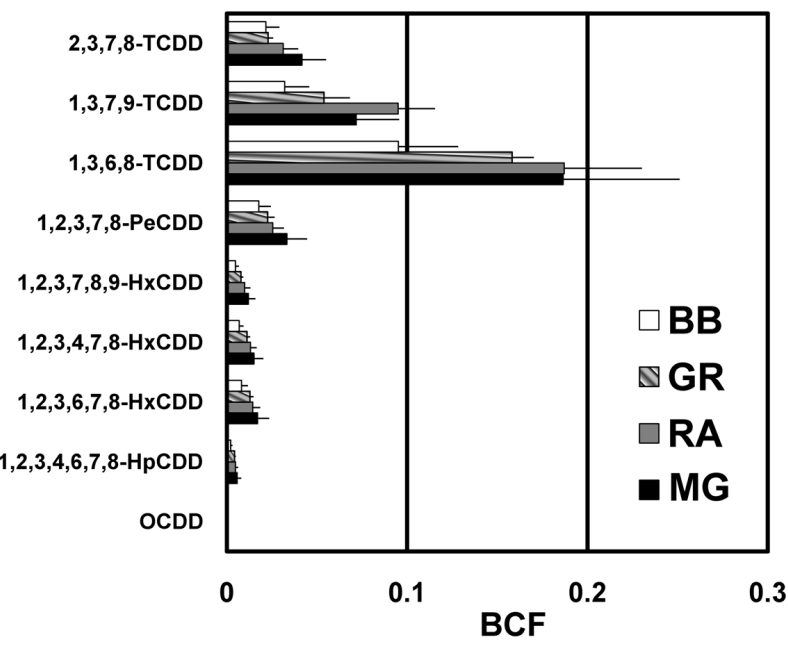
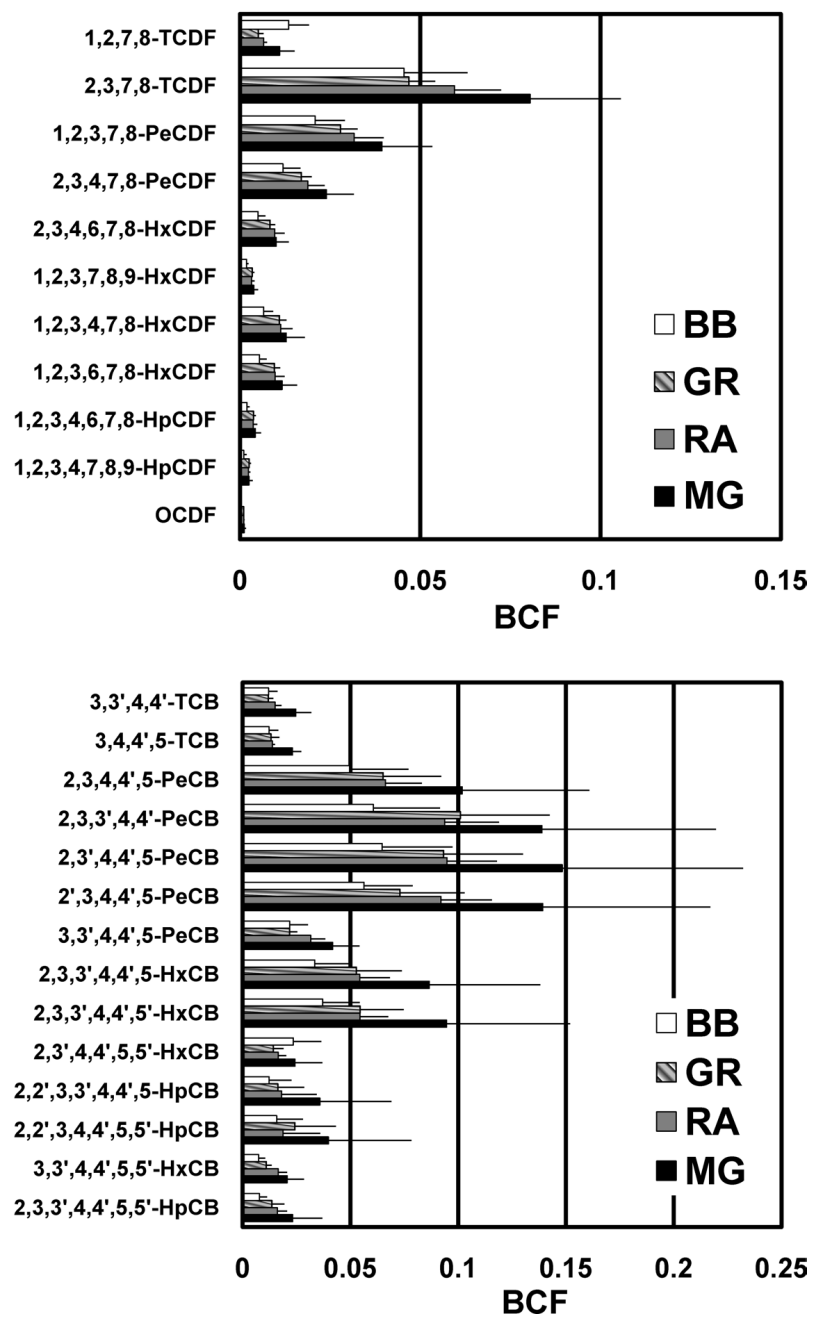

Fig. 2. BCFs for PCDDs (A), PCDFs (B), and PCBs (C) in the aerial parts of nine cultivars of zucchini plants of subspecies ovifera (left) and pepo (right). BCFs were calculated by dividing the concentration of each dioxin congener in plants by its concentration in soil. Values are the means \pm SDs. 
Table 2. Correlation coefficients for the relationship between BCFs in nine cultivars and $\log K_{\mathrm{ow}}$ values for PCDDs, PCDFs, and PCBs

\begin{tabular}{|c|c|c|c|c|c|c|c|c|c|}
\hline \multirow{3}{*}{ Compound } & \multicolumn{9}{|c|}{ Correlation coefficient } \\
\hline & \multicolumn{5}{|c|}{ ovifera } & \multicolumn{4}{|c|}{ реро } \\
\hline & PG & ST & SB & SR & $\mathrm{ZP}$ & BB & GR & RA & $\mathrm{MG}$ \\
\hline PCDD & $-0.709^{a)}$ & -0.782 & -0.675 & -0.624 & -0.654 & -0.698 & -0.636 & -0.648 & -0.648 \\
\hline PCDF & -0.532 & -0.579 & -0.682 & -0.644 & -0.667 & -0.702 & -0.572 & -0.578 & -0.578 \\
\hline $\mathrm{PCB}$ & -0.759 & -0.647 & -0.382 & -0.361 & -0.367 & -0.398 & -0.341 & -0.358 & -0.358 \\
\hline
\end{tabular}

${ }^{a)}$ Italicized values indicate significant correlations.

(A)

(B)
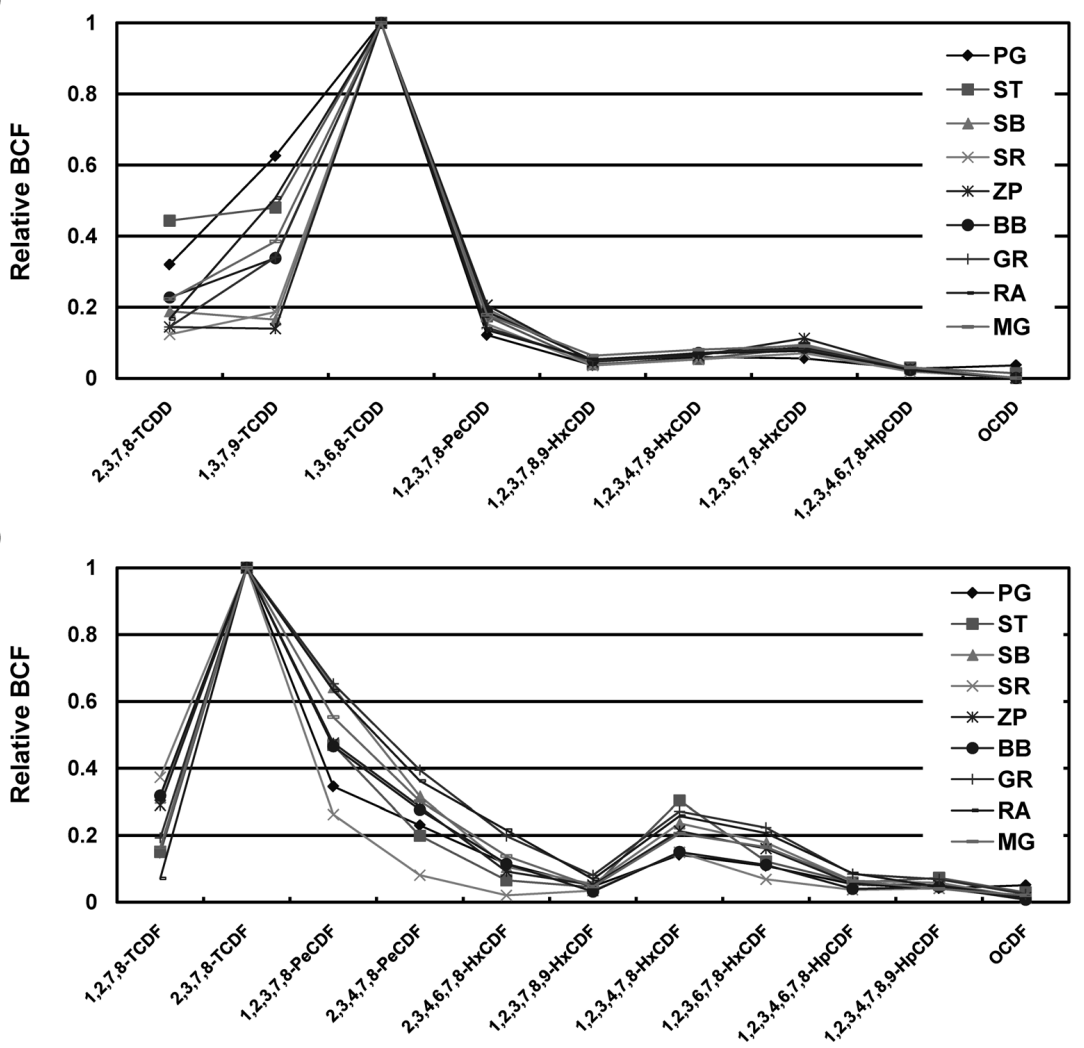

(C)

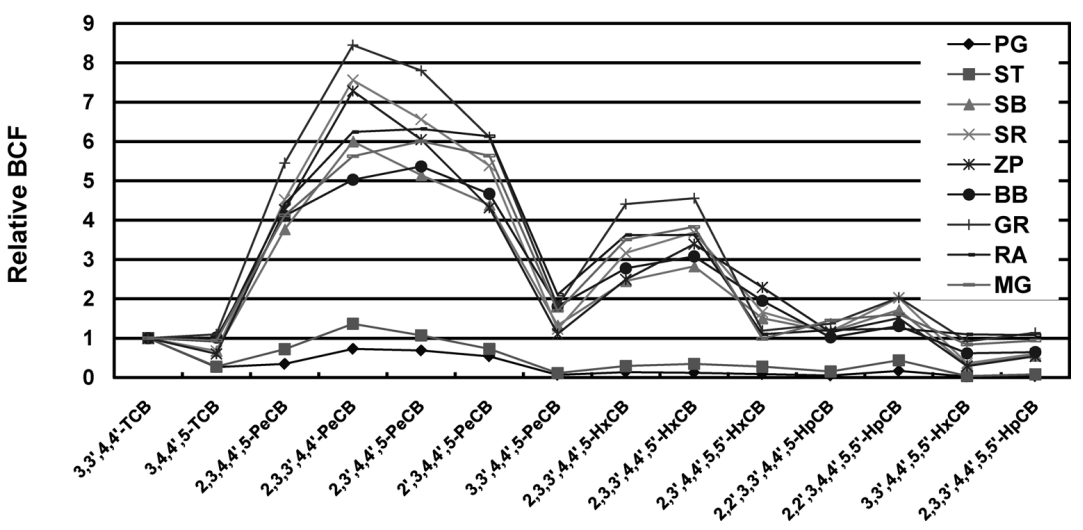

Fig. 3. Relative BCFs of PCDDs (A), PCDFs (B), and PCBs (C) accumulated in the aerial parts of nine cultivars of zucchini plants. Relative BCFs were calculated by dividing the BCF of each PCDD, PCDF, or PCB congener by the BCF of the PCDD, PCDF, or PCB, respectively, with the highest $\mathrm{BCF}$ in $\mathrm{PG}$. 
lization of contaminants from soil organic matter, (3) adsorption onto the root surface, (4) absorption into the root cells, (5) translocation to the aerial parts, and (6) metabolism and accumulation. Differences in these steps are likely to be responsible for cultivar-specific accumulation.

The roots of many plants exude organic acids that desorb and solubilize DDE from soil organic matter; ${ }^{15)}$ citric and oxalic acids at $0.05 \mathrm{M}$ have the largest impact on desorption of DDE from weathered soil in comparison with just water containing no organic acids. ${ }^{16)}$ Therefore, variation in the nature and amounts of the components of root exudates (e.g., organic acids) is likely to affect cultivar-specific accumulation in the second step, owing to differential desorption and solubilization of dioxins and dioxin-like compounds. This likelihood is supported by results indicating that the relative BCFs in hydroponic growth media are lower than those in soil. ${ }^{17)}$ Consequently, we believe that the desorption and solubilization step is an important determinant of quantitative cultivar-specific accumulation of dioxins and dioxin-like compounds, causing large variations in the accumulation of total PCDDs, PCDFs, or PCBs.

Because distinguishing between the adsorption and absorption of dioxins and dioxin-like compounds in roots is difficult, the congener selectivity of steps 3 and 4 remains to be elucidated. In the endodermis of plant roots, there are casparian strips composed of a wax-like hydrophobic compound (suberin). These strips confer selectivity in the loading of heavy metals to the xylem, and the strips may also be involved in the selective absorption of hydrophobic compounds. ${ }^{18)}$ In fact, the accumulation of some metals and DDE in the aerial parts of the plants has been shown to be correlated. ${ }^{16}$

The translocation factor (TF) of a compound indicates the efficiency of its translocation from roots to aerial parts. The TF patterns of PCBs in GR grown hydroponically, in which ortho-substituted congeners accumulated specifically, ${ }^{17)}$ were similar to the BCF patterns of PCBs in GR observed in our study. Moreover, preferential accumulation of $(+)$-cis-chlordane over $(-)$-cis-chlordane and $(-)$-trans-chlordane over $(+)$-trans-chlordane in the aerial tissues of the zucchini plants has been observed, ${ }^{19}$ ) indicating that these compounds are enantioselectively translocated and metabolized. Consequently, it is possible that, in zucchini plants, there may be some mechanism for qualitative cultivar-specific accumulation of hydrophobic compounds in steps 5 and 6 , causing the different BCF patterns among cultivars. Recently, it was reported that there are proteins that bind and dissolve dieldrin in the xylem sap of cucurbitaceous plants. ${ }^{20)}$ Selective translocation of POPs in xylem sap may be accomplished by means of selective binding by these proteins.

Poplar trees can metabolize 4-monochlorobiphenyl into its hydroxylated metabolites. ${ }^{21)}$ Furthermore, poplar trees grown hydroponically metabolize $3,3^{\prime}, 4,4^{\prime}$-TCB rapidly to 6-hydroxy-3,3',4,4'-TCB. ${ }^{22)}$ Selective metabolism of PCB con- geners may be responsible for the structure-specific accumulation in observed in this study.

Here, we observed inter-cultivar differences in the accumulated concentrations and varieties of PCDDs, PCDFs, and PCBs in the aerial parts of $C$. pepo plants. In particular, structure-selective accumulation of PCB congeners was observed in some cultivars. We believe that the cultivar specificity of accumulation may have arisen from several accumulation steps. The detailed mechanisms of the selectivity will have to be clarified by further investigations, and such clarification can be expected to lead to the development of effective methods for phytoremediation of hydrophobic contaminants.

\section{Acknowledgements}

This work was funded in part by a Grant-in-Aid for Scientific Research A from the Ministry of Education, Culture, Sports, Science and Technology of Japan (no. 17208029). We thank Ms. Emiko Iizumi for technical assistance.

Supplemental Fig. S1 and Tables S1 and S2 are available in the online publication at http://www.jstage.jst.go.jp/browse/jpestics/.

\section{References}

1) P. F. Hoekstra, T. M. O'Hara, A. T. Fisk, K. Borga, K. R. Solomon and D. C. Muir: Environ. Pollut. 124, 509-522 (2003).

2) http://www.env.go.jp/chemi/pops/treaty.html

3) International Agency for Research on Cancer (IARC): Polychlorinated dibenzo-para-dioxins and polychlorinated dibenzofurans. IARC Monogr. Eval. Carcinog. Risks Hum. 69 (1997).

4) K. Yamazaki and H. Inui: "Trends in Bioremediation and Phytoremediation," ed. by G. Plaza, Kerala, India, pp. 339-354, 2011.

5) T. Otani, N. Seike and Y. Sakata: Soil Sci. Plant Nutr. 53, 86-94 (2007).

6) A. Hülster, F. M. Jochen and M. Horst: Environ. Sci. Technol. 28, 1110-1115 (1994).

7) M. I. Mattina, W. Iannucci-Berger and L. Dykes: J. Agric. Food Chem. 48, 1909-1915 (2000).

8) J. C. White, Z. D. Parrish, M. Isleyen, M. P. Gent, W. IannucciBerger, B. D. Eitzer and M. I. Mattina: Environ. Toxicol. Chem. 24, 987-994 (2005).

9) M. I. Mattina, W. Iannucci-Berger, C. Musante and J. C. White: Environ. Pollut. 124, 375-378 (2003).

10) J. C. White, X. Wang, M. P. Gent, W. Iannucci-Berger, B. D. Eitzer, N.P. Schultes, M. Arienzo and M. I. Mattina: Environ. Sci. Technol. 37, 4368-4373 (2003).

11) M. I. Mattina, B. D. Eitzer, W. Iannucci-Berger, W.-Y. Lee and J. C. White: Environ. Toxicol. Chem. 23, 2756-2762 (2004).

12) H. Inui, T. Wakai, K. Gion, Y.-S. Kim and H. Eun: Chemosphere 73, 1602-1607 (2008).

13) H. Inui, H. Sasaki, N.-H. Chua and H. Ohkawa: Transgenic Res. 18, 899-909 (2009).

14) T. Fujisawa: J. Pestic. Sci. 27, 279-286 (2001) (in Japanese).

15) X. Wang, J. C. White, M. P. Gent, W. Iannucci-Berger, B. D. Eitzer and M. I. Mattina: Int. J. Phytoremed. 6, 363-385 (2004).

16) J. C. White, M. I. Mattina, W.-Y. Lee, B. D. Eitzer and W. Ian- 
nucci-Berger: Environ. Pollut. 124, 71-80 (2003).

17) H. Inui, T. Wakai, K. Gion, K. Yamazaki and H. Eun: Biosci. Biotechnol. Biochem. in press (2011).

18) L. Taiz and E. Zeiger (eds.): "Plant Physiology," 3rd Ed., Baifukan, Tokyo, p. 50, 2004.

19) J. C. White, M. I. Mattina, B. D. Eitzer and W. Iannucci-Berger: Chemosphere 47, 639-646 (2002).

20) H. Murano, T. Otani and N. Seikei: Environ. Toxicol. Chem. 29, 2269-2277 (2010).
21) G. Zhai, H. J. Lehmler and J. L. Schnoor: Environ. Sci. Technol. 44, 3901-3907 (2010).

22) J. Liu, D. Hu, G. Jiang and J. L. Schnoor: Environ. Sci. Technol. 43, 7503-7509 (2009).

23) D. W. Hawker and D. W. Connell: Environ. Sci. Technol. 22, 382-387 (1988).

24) J. Chen, X. Quan, Z. Yazhi, Y. Yan and F. Yang: Chemosphere 44, 1369-1374 (2001) 